\title{
The influence of circulation change on sedimentary records of the Paleocene- Eocene Thermal Maximum
}

\author{
Donald E. Penman ${ }^{1}$ and Sandra Kirtland Turner²
}

\begin{abstract}
The Paleocene-Eocene Thermal Maximum (PETM, 56 Myr BP) was a rapid greenhouse-gas-driven global warming event highlighted for comparison to anthropogenic climate change. Proxies and modeling indicate that changing patterns of global overturning circulation overprinted paleoceanographic records of this event.
\end{abstract}

\begin{abstract}
In 1991, Kennett and Stott published a groundbreaking record of the carbon and oxygen isotope composition of foraminifera from Southern Ocean deep-sea sediments spanning the Paleocene-Eocene boundary. They observed striking negative excursions in both isotopic systems, unlike any rapid shifts known from the paleoceanographic record, coincident with the largest benthic extinction of the Cenozoic. The oxygen isotopes indicated a sudden warming of both surface and deep Antarctic waters, while the carbon isotope excursions (CIE) suggested a collapse in vertical $\delta^{13} \mathrm{C}$ gradients. Those authors concluded that changes in the global overturning circulation must be the cause of these unusual paleoceanographic observations and the extinction - but a proliferation of coeval sedimentary records in the decades since has transformed this interpretation.
\end{abstract}

From local findings to global observations The CIE and warming first recognized in the Southern Ocean have now been observed globally from both the marine and terrestrial realms (Fig. 1; see e.g. Mclnerney and Wing 2011 for a compilation), in organic and inorganic carbon, and coincide with evidence for global ocean acidification (Babila et al. 2018; Zachos et al. 2005), large reorganizations of the hydrologic cycle (Wing et al. 2005: Zachos et al. 2003), and biotic turnover both on land and in the sea (Speijer et al. 2012). The modern interpretation holds that this event (now known as the Paleocene-Eocene Thermal Maximum or PETM) was driven by the geologically rapid (within thousands of years) addition of a large mass (thousands of gigatons) of isotopically light carbon into the atmosphere and ocean. Without the global coverage provided by more recent observations, Kennett and Stott did not know what triggered their proposed change in circulation, but in a sense their interpretation still holds: marine records of the PETM reflect not only global carbon cycle processes, but also the regional effects imparted by the changes in ocean circulation that we still think occurred during the PETM.

\section{Basinal asymmetry in pelagic PETM sedimentary records}

Comparison of PETM deep-sea records reveals several regional differences in lithology and geochemistry that illustrate the profound influence of changing ocean circulation during the event. $\mathrm{CaCO}_{3}$ dissolution is a hallmark of pelagic PETM records, characterized by a temporary decline or absence of the calcareous microfossils that typically constitute pelagic sediments, resulting in a conspicuous clay layer. This dissolution is an expected consequence of $\mathrm{CO}_{2}$ addition to seawater, which lowers $\mathrm{pH}$ and carbonate saturation state $(\Omega)$ in tandem. Paleoceanographers often quantify the extent of dissolution by reconstructing the shoaling of the carbonate compensation depth (CCD), the "snowline" of the ocean below which carbonates are absent from sediments. However, there are significant regional differences in the extent of PETM $\mathrm{CaCO}_{3}$ dissolution (or the existence and thickness of clay layers). In the South Atlantic, PETM clay layers identified from a depth transect of ocean drilling sites indicate that the CCD shoaled by greater than $2 \mathrm{~km}$ and suggest the dissolution of $\mathrm{CaCO}_{3}$ over huge regions of the seafloor (Zachos et al. 2005). In contrast, a similar depth transect in the subtropical North Pacific shows comparatively limited $\mathrm{CaCO}_{3}$ dissolution, constraining the CCD shoaling in that basin to less than $0.5 \mathrm{~km}$ (Colosimo et al. 2005; Zeebe and Zachos 2007). Much of this basinal asymmetry can be explained by a reorganization of deep-sea circulation. Deep water becomes more corrosive to $\mathrm{CaCO}_{3}$ (lower $\Omega$ ) with age due to the accumulation of respired organic carbon, such that the modern CCD in the deep North Pacific (filled with the ocean's oldest seawater) is $\sim 1 \mathrm{~km}$ deeper than in the North Atlantic (which, as a region of deep-water formation, contains the youngest deep water). Using a sediment model forced with records of varying $\mathrm{CaCO}_{3}$ weight percentages (wt. \%) at different globally distributed pelagic sites, Zeebe and Zachos (2007) determined that $\mathrm{CaCO}_{3}$ undersaturation at the peak of the PETM was more severe in the Atlantic than in the Pacific - the opposite of the modern pattern. Those authors concluded that deep water circulation patterns must have been reversed (relative to the modern configuration) during the acidification phase of the PETM. This idea was expanded upon by the

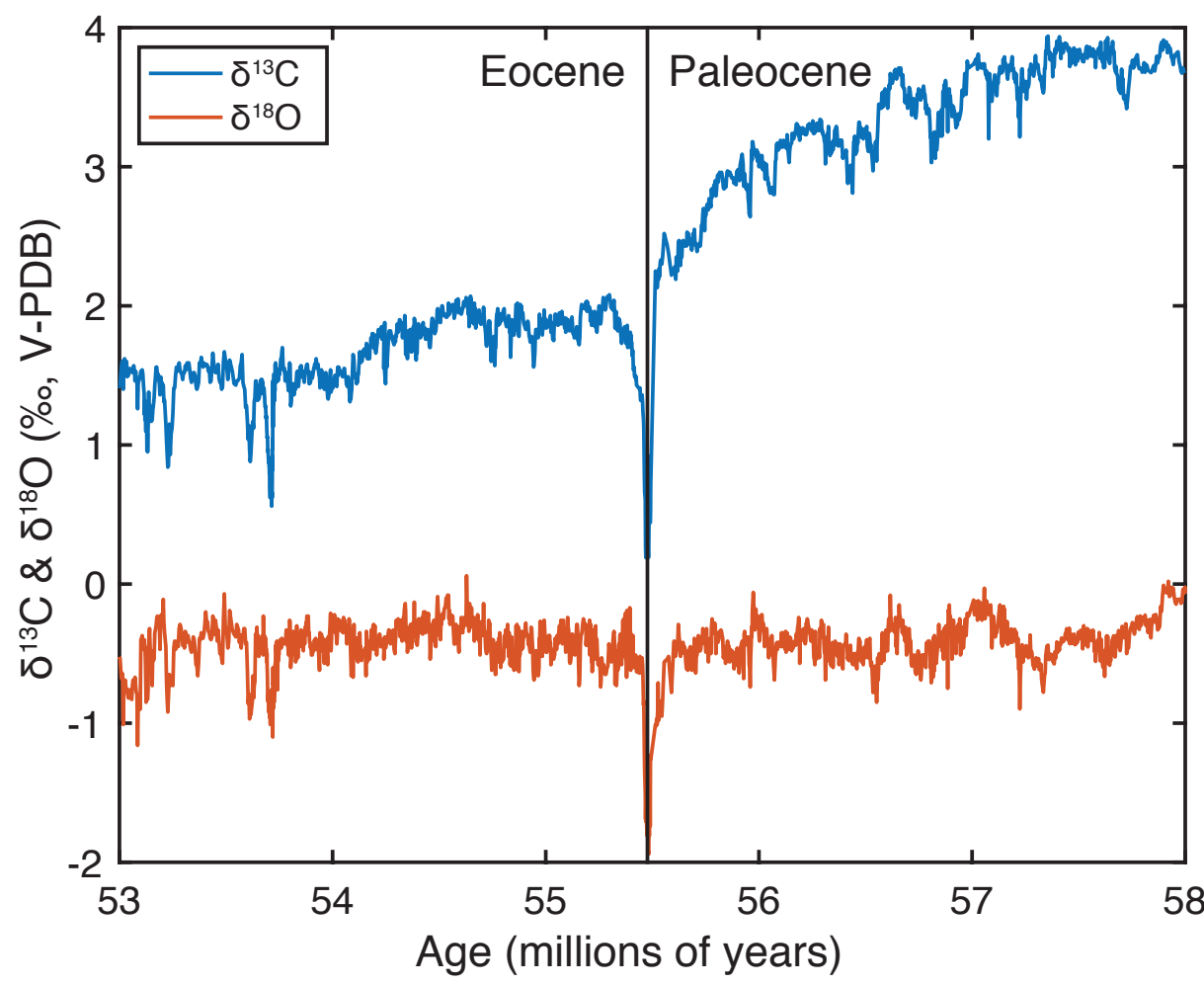

Figure 1: Bulk-sediment carbon and oxygen isotope stratigraphy of Site 1262 from the late Paleocene through the early Eocene (Zachos et al. 2010). The large negative excursions in both isotope systems at the PaleoceneEocene boundary represents the PETM. 


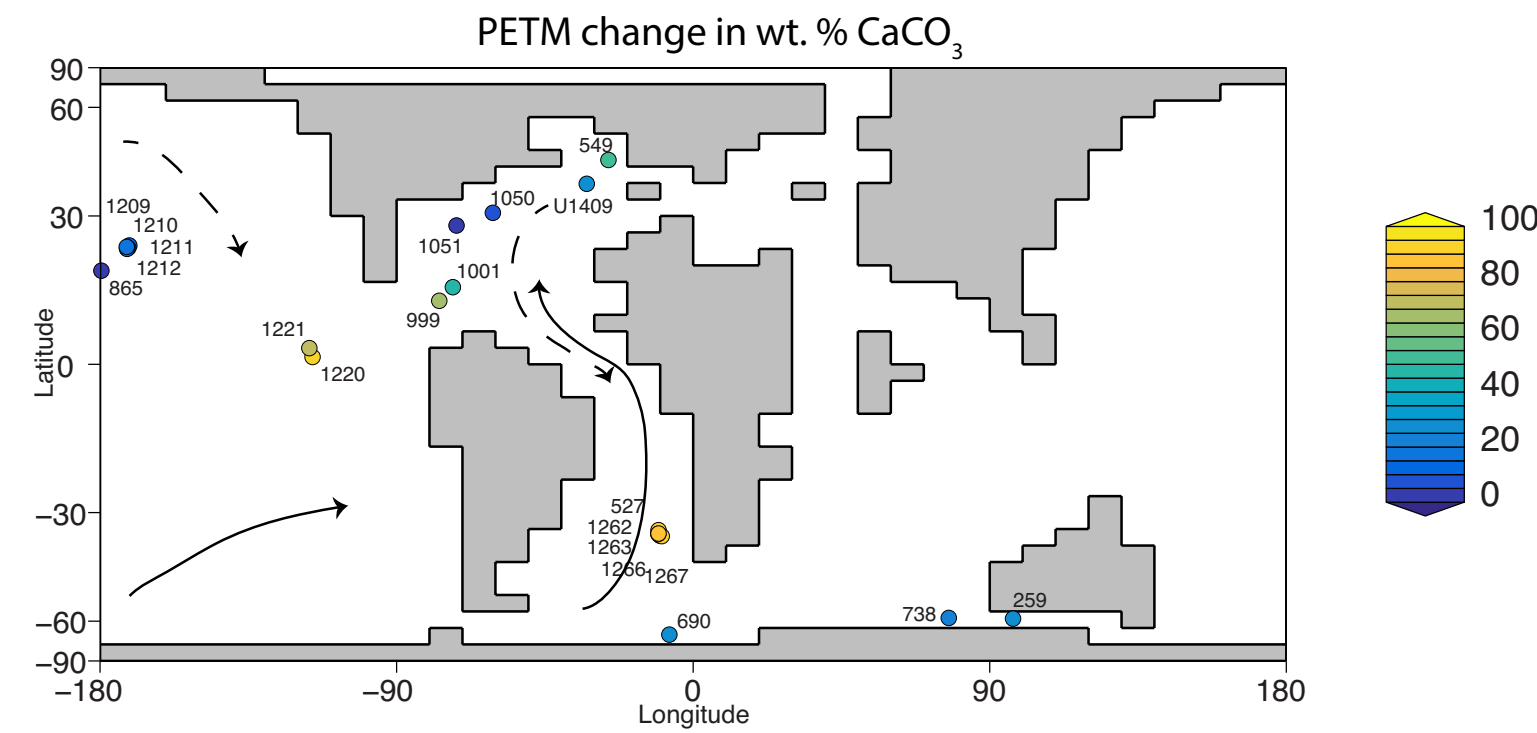

Figure 2: Change in pelagic sedimentary wt. \% $\mathrm{CaCO}_{3}$ over the PETM (colored circles) plotted on the cGENIE model Paleocene land mask (Panchuk et al. 2008). Data were compiled from Zeebe and Zachos (2007) and Panchuk et al. (2008), but see references therein for original records. Arrows show inferred circulation for pre-event (solid lines) and PETM (dashed lines) based on changing $\delta^{13} \mathrm{C}$ gradients and basinal asymmetry in $\mathrm{CaCO}_{3}$ dissolution.

PETM carbon-cycle simulation of Zeebe et al. (2009), who implemented a transient shift in the locus of deep-water formation from the Southern Ocean to the North Pacific.

\section{Disparate benthic CIE magnitudes}

Another hallmark of the PETM that is susceptible to overprinting by changing ocean circulation is the size of the benthic foraminiferal $\mathrm{CIE}$, which varies significantly from site to site (McInerney and Wing 2011; Nunes and Norris 2006). In theory, the benthic CIE due to a rapid carbon release should simply reflect the mass and $\delta^{13} \mathrm{C}$ of the carbon input, and be relatively homogenous throughout the deep sea, given that typically low pelagic sedimentation rates are unlikely to resolve differences on timescales shorter than ocean mixing (1-2 kyr). The $\delta^{13} \mathrm{C}$ of dissolved carbon in deep seawater decreases as it ages due to the accumulation of isotopically light respired organic carbon. In the modern ocean, this leads to a $1 \%{ }^{13} \mathrm{C}$ difference between young North Atlantic deep water and old North Pacific deep water. Deep-water circulation is hence a powerful lever on regional benthic $\delta^{13} \mathrm{C}$ - an abrupt reversal of the modern deep-water aging gradient would force Pacific benthic $\delta^{13} \mathrm{C} 1 \%$ heavier and Atlantic $\delta^{13} \mathrm{C} 1 \%$ lighter in the long term. An abrupt reorganization of deep-water circulation patterns at the PETM onset could similarly help explain the range of deep-ocean benthic foraminiferal $\mathrm{CIE}$ sizes observed globally, which span $0.5 \%$ to 3.5\% (Mclnerney and Wing 2011). Nunes and Norris (2006) produced a global compilation of deep-ocean benthic CIE records and argued that the generally smaller CIE magnitude in the Northern Hemisphere compared to the Southern Hemisphere resulted from a switch in the locus of deep-water formation from the Southern Ocean to the North Atlantic. Additional complications remain, including truncation of the base of the event due to carbonate dissolution at some sites (leading to an apparently smaller CIE) and the role of bioturbation (mixing by benthic organisms) but changing ocean circulation patterns are clearly a factor in the disparate magnitude of benthic CIEs.

\section{Additional geochemical indicators}

While deep-sea records of $\mathrm{CaCO}_{3}$ wt. \% and $\delta^{13} \mathrm{C}$ are most common, there is evidence for ocean circulation impacting other PETM geochemical records as well. Proxies for deep-ocean oxygen (Pälike et al. 2014) and patterns of silica burial (Penman et al. 2019) indicate asymmetry between the Atlantic and Pacific basins during the PETM. Neodymium isotopes, a quasi-conservative tracer of ocean circulation, may even more directly indicate changes in deep-ocean ventilation associated with shifting patterns of overturning circulation (Abbott et al. 2016; Blaser et al. this issue).

\section{Mechanisms for PETM circulation change from ocean-physics models} Sedimentological evidence suggests that a change in deep-ocean circulation was likely during the PETM, and physical models provide possible causal mechanisms. Using a model of ocean physics forced offline by an atmospheric general circulation model, Bice and Marotzke (2002) explored the role that the hydrologic cycle might have played in linking global warming to changes in ocean circulation at the PETM. With warming, the hydrologic cycle intensifies, transporting more water vapor from low to high latitudes. This increases the poleward latent heat flux and redistributes evaporation and precipitation globally, changing patterns of sea-surface salinity. Both of these (heat and freshwater transport) change the density gradients of surface seawater, which makes surface waters in different regions of the ocean more or less susceptible to sink and form deep water. Bice and Marotzke's experiments favored a switch from Southern to Northern Hemisphere deep-water formation during peak PETM forcing, broadly consistent with the hypotheses proposed by Zeebe et al. (2009) and Nunes and Norris (2006), but the exact locus and flux of northern deep-water formation is sensitive to uncertain paleogeography and is still debated. Numerical modeling of an instantaneous warming event simulated with the UVic Earth system model of intermediate complexity by Alexander et al. (2015) provides a consistent and more detailed scenario in which corrosive North Atlantic bottom water spills into the South Atlantic with the onset of North Atlantic deep-water formation over the several thousand years following instantaneous $\mathrm{CO}_{2}$ release.

Together, modeling and geochemical study of the PETM demonstrate that it is crucial to consider changes in the global overturning circulation, and not just global carbon cycle processes, in the interpretation of sedimentary records of ancient climate perturbations.

\section{AFFILIATIONS}

'Geology and Geophysics, Yale University, New Haven, CT, USA

${ }^{2}$ Department of Earth Science, University of California Riverside, USA

\section{CONTACT}

Donald E.Penman: donald.penman@yale.edu

\section{REFERENCES}

Abbott AN et al. (2016) Clim Past 12: 837-847

Alexander Ket al. (2015) Nat Geosci 8: 458-461 Babila T et al. (2018) Philos T R Soc A 376: 20170072 Bice KL, Marotzke J (2002) Paleoceanography 17: 1018 Colosimo AB et al. (2005) In: Bralower TJ et al. (Eds) Proc. ODP, Sci. Results, Volume 198. Ocean Drilling Program

Kennett JP, Stott LD (1991) Nature 353: 225-229 Mclnerney FA, Wing SL (2011) Annu Rev Earth PI Sc 39 : 489-516

Nunes F, Norris RD (2006) Nature 439: 60-63 Pälike C et al. (2014) Geochem Geophy Geosy 15: 1038-1053

Panchuk K et al. (2008) Geology 36: 315-318

Penman DE et al. (2019) Paleoceanogr Paleocl 34: 287-299

Speijer R et al. (2012) Austrian J Earth Sci 105: 6-16

Wing SL et al. (2005) Science 310: 993-996

Zachos JC et al. (2003) Science 302: 1551-1554

Zachos JC et al. (2005) Science 308: 1611-1615

Zachos JC et al. (2010) Earth Planet Sc Lett 299: 242-249

Zeebe RE, Zachos JC (2007) Paleoceanography 22: PA3201

Zeebe RE et al. (2009) Nat Geosci 2: 576-580 